\title{
Analogical Rationality in Social Sciences
}

\author{
Carlos-Adolfo Rengifo-Castañeda
}

\begin{abstract}
This research article proposes a conception of analogical rationality, which operates in the social sciences as well as in the natural sciences, according to "epistemic, ontological and pragmatic" conditions. According to this, in this paper it is intended: First, to account for analogical rationality according to epistemic, ontological and pragmatic conditions, contrasting with this, the classical conception of rationality. And second, on the basis of the above, to enable by analogical rationality a status of scientificity for the social sciences by justifying rational beliefs and decisions, according to this tripartite condition
\end{abstract}

Keywords: Epistemology, rationality, science, epistemic and pragmatic

\section{Introduction}

For the purposes of understanding what is proposed here as a analogical rationality, and on the basis of the heading with respect to the notion of analogy and its importance in the cognitive processes, as well as in the criteria relating to the choice and rational evaluations, it is necessary in this article from a methodological perspective, the following aspects: Firstly, to give a brief account of the concept of analogy that characterizes this conception of rationality. Secondly: to expose what such analogical rationality is in the epistemic, ontological and pragmatic conditions, from the ideas of Evandro Agazzi. Finally, to conclude that the rationality in the social sciences - as in any other science, operates in a different way, but even in the differences, this procedure is carried out in a similar and proportional way, in other words, analogicalue, according to particular and specific conditions, in accordance with the ontological regions of each science and its criteria of rigor and objectivity.

Regarding the notion of analogy, it can be noted that it is present in a huge part of the history of the West philosophy, a scenario in which exists various meanings that, in a certain way, place it in the problems related to knowledge in general. Thus, the analogy permeates different fields of knowledge "even more the social and the social and human sciences" (Beuchot, Hermeneutics, analogy and symbol, 2004, p. 15) allowing the purposes of this proposal, "an analogicalicity from reality and knowledge, but according to the grade and differences, in accordance to the fields and orders that are performed" (Beuchot 2004, p. 15) and recognizing for this purpose, the different action modes of each science under the- rigor and objectivity- but structured in a similar and proportional way.

It has been said about this notion of analogy in the history of western philosophy that is everything what is preached about the substances or accidents in a similar way, not identical, distancing them, on the one hand, from the univocity and on the other hand, from the equivocal aspect. About the univocity, so as it was mentioned, it is the one that says things in a way only guided for this reason, probably, because of arbitrariness and reductionism -this is the case, the classical rationality itself. And being away from the equivocal, since the meaning is one that deals with misleading claims about the substances among them, but in a different or contrary way to what they are. It is then with the analogy, as Augusto C, Cárdenas cited by Beuchot and Santamaria "a way of intermediate meaning between the unambiguity and the equivocal (Cárdenas 23)" (Beuchot \& Santamaría-Velasco, 2015, pág. 326)

This relationship - in accordance with the analogy ${ }^{4}$-, using the criteria of similarity between one thing in proportion to another, allowing to consider, finally, that the conception of analogical rationality sets the proportional similarity in the way the rationality proceeds in a science, similarly to the other science - even, being different sciences with different or similar objects. How Ferrater Mora says, the analogy consists in "the attribution of the same predicates to various objects, but this attribution should not be understood as a clear determination of these objects, but as the expression of accordance, likeness or correlation established between them" (Ferrater Mora, 2000, pág. 100) 


\section{The analogical rationality according to, epistemic ontological and pragmatic conditions.}

\section{The analogical rationality}

"The analogy is the machine through which the cognitive values

Related to issues of importance and reasonableness

They are also recruited to our criteria of acceptability"

(Rescher, the struggle of the systems, 1995)

\section{The epistemic conditions:}

The problem of scientific rationality in the epistemic conditions leads to this proposal by the cognitive aspect of science, that is to say, the issue of the truth, and specifically by the criteria of rigor and objectivity that "can be summarized under the term of rationality" (Agazzi E. , 1996, p. 202), according to a particular body of knowledge.

These epistemic conditions in the analogical rationality context serve as intellectual and cognitive orientations, which are required in the epistemic process of all science. However, these conditions do not have any a priori or universal doctrinal claim regarding to the sciences; but, on the contrary, its character is clearly contingent, pragmatic, contextual, and limited to the ontological regions of each particular science, in accordance with the criteria of rigor and objectivity inherent in a certain science.

Nevertheless, in relation to the criteria of rigor in the scientific knowledge, it is intended to give an account that it is about a journey of justification for all those epistemic and unique statements, given to the interior of a knowledge body, and from which it faces a set of problems. With this, it aims an attempt to give good reasons about what is preached according to a method established by a scientific system; a subject of great relevance, since it leads to the recognize that "each science has [...] an own way of characterizing the rigor requirements. This is true, above all, because it pertains the establishment of the checking the criteria of the data" (Agazzi E. , 1996, p. 36). This rigor will be defined as the set of methodologies stipulated by each science, either natural or social, in its attempt to determine the how to give an account of the facts and data in scientific research in an appropriate way.

For example, in the social sciences, according to a historical approach, the methodology which will give account of the rigor of the science will determine "the criteria to search for sources, to evaluate its authenticity, to establish the dating, to proceed to comparative tests of its contents, to interpret them within the context of its origin, etc." (Agazzi E. , 2014, pp. 3-4)

In this way, as it has already been mentioned, nor the psychology, sociology, anthropology, archeology, history, or any other science in particular - to mention a few-, uniquely share the same criteria for securing the data or the establishment of logical mappings between their assumptions and propositions. However, they share in proportion of its concerns in relation to an own rigor criteria.

This begins to corroborate the viability of the analogical rationality noting that each science, either social or human, is immersed in specific, particular, unique and different conditions, in a way to describe the requirement of the scientific rigor and its judgment elements in relation to the objects -social facts- that are intended to justify, and are cropped off the state of issues from the social reality. In addition, such conditions, as will be explained later, determine the requirement of scientific objectivity in accordance with their objects - according to analogical reference.

\section{Ontological Conditions:}

In order to continue developing this proposal for a analogical rationality in relation to the ontological conditions expressed through regional ontologies of each science in particular, it is necessary in the first place, to give an account of the requirement of objectivity in science; secondly, to describe the relationship between things and objects in science and finally, in the third place, to comment the problem of the reality in the sciences in a general way.

Objectivity according to Agazzi is understood in two ways. (I) the objectivity, as a consequence of the intersubjective agreement (objectivity weak). This agreement - for example, is necessary for the processes of understanding and explanation in the social sciences. It is only enough, according to this consideration, that knowledge can be valid for all as 
a subjective type invariance (Agazzi E. , 1978, p. 406). (li) The objectivity and the determination of the objects, in other words, the description of which is inherent to the object (objectivity strong) (ontological aspect of knowledge) the moment in which the ontological reference enters into dialog with criteria of referentiality and operationality of the objects. This issue of the objectivity of great importance for Agazzi has been developed in a comprehensive manner and sufficient, in his book Scientific objectivity and Its Contexts (2014), he exposes his conception of the things, the objects, the reality and the truth in science among other issues of great relevance to its epistemological conception.

However, in order to develop the requirement of objectivity and its incidence in the social sciences, it is necessary to make a clear distinction between the things that are part of the reality (ontology), and the objects, for example, of a social nature determined by each social science, according to some of their specificities (ontological regions).

In this order of ideas, it is suggested that, on the one hand, they are everything to which on a daily basis makes reference to the human consciousness, while the objects, on the other hand, without abandoning their initial entity of being things, become objects according to the ontological, epistemic and pragmatic conditions that determine the point of view of each science - whether natural or social-, and their specific operational criteria. With this, it is suggested that the "'things' are approached and described in different sciences by means of different objectifications that express the viewpoints or the 'wholes' of single sciences" (Agazzi E. , Scientific objectivity and Its Contexts, 2014, p. 146).

This problem of the Objectivity in accordance with the things, can only be achieved according to the gestalten perspectivism; promoting in this way, the cognitive process of science in the context of the partiality of the truth, as explained in the following quote:

[...] This takes place through the application of operational criteria of objectification to 'things.' But this is not the logically primitive fact, since these criteria are devised only within a particular Gestalt, in which several concepts are organised into a unity. Sometimes this Gestalt is of a low level and is almost entirely constituted by empirical and sensory features; but in almost all the sciences much more complex Gestalten are introduced by virtue of an intellectual synthesis. In the case of these more complex constructions, some of the features entering the Gestalt must be equipped with operational conditions for testing. Only if these requirements are satisfied can a general perspective on things, a conceptual space, be promoted to the level of being the domain of discourse of a particular science, and make it practically possible for 'things' to enter the domain of objects of science, and actually be investigated by it. (Agazzi E. , 2014, p. 146)

As it was mentioned above, each social science determines the state of things within the whole of the social reality, their social objects capable of being known as his own point of view, through "a certain number of predicates (or the names of properties, relations, functions) that constitute the conceptual background of that particular science" (Agazzi E. , 1996, p. 41), That is to say, according to various epistemic conditions in accordance with ontological conditions enabled by operational and referential criteria.

These tools determine those "regional ontologies" with regard to which the concept of truth is "relativized", in the sense that the truth of a proposition is relative to its intended "referential domain". In this way the relation between thinking and being becomes the more precise relation between thoughts (the concrete contents of acts of thinking) and ontologies (that is, the delimited aspects of reality that are actually intended by an act of thinking). (Agazzi E. , 2011, p. 29)

These particular points of view, for example, about the social reality, make things the objects capable of being known, that is to say, its ontological referents in accordance to a framework of epistemic and operational criteria, like an analogical expression of rationality in each particular science. It is, therefore, a set of tools that allows to operationalize the various ontological regions:

It reflects the idea that knowledge always is knowledge of something and scientific knowledge essentially consists in reducing this general scope of knowledge to a much more restricted and delimited field, the field of the specific objects of the single disciplines. In other words, whereas intersubjectivity focuses on the epistemological aspect of knowledge, this hint at reference focuses on the ontological aspect of knowledge. (Agazzi, Scientific Realism Within Perspectivism Perspectivism and Within Scientific Realism, 2016, p. 360)

Based on the above, to make easier to understand how the knowledge of objects in the social sciences, which have been cut out of the totality of things that shape the reality (social), after applying a set of referentiality and operationality criteria, which ultimately provide objectivity in social science. 


\section{Pragmatic Conditions:}

Considering a conception of analogical rationality based also in pragmatic terms requires in accordance with the budgeted in this article, the following aspects: $i$ ), to recognize clearly from a contextual perspective the relevance of the intersubjective agreements (weak objectivity). ii), to observe the intersubjective agreement, on the basis of certain operational and use criteria (strong objectivity). All of this to finally settle the notion of scientific objectivity in the social sciences.

1) To recognize the intersubjective agreements in relation to the scientific objectivity implies necessarily that such agreements are carried out on the basis of the plurality of the observations achieved by subjects; being this aspect very important as Agazzi said, since this agreement exceeds the determination of objects made by an individual, knowing a real object and objectively exists "to more than one subject or for the same subject in different situations" (Agazzi E. , 1978 , p. 410). Thus, recognizing this intersubjectivity as one of the criteria that allow you to ratify that rationality operates in pragmatic terms, indicates how these subjects according to their experience, interest and context, they agree to justify their beliefs, as well as to choose or act rationally. With respect to this agreement, Agazzi asserts:

Aquí es preciso no confundir este hecho con una afirmación del convencionalismo: no se trata de que, en un cierto momento, los científicos se pongan de acuerdo para hacer o decir ciertas cosas, para usar o rechazar ciertos instrumentos; sino que, mucho más simplemente, tal acuerdo se produce de hecho de un modo que no podría ser predeterminado a priori. Quien se sorprenda de esto no reflexiona suficientemente sobre la circunstancia de que la ciencia (y en general, todo conocimiento) no surge en el vacío, sino que procede siempre de un conocimiento precedente, utilizando lo que ya está disponible. Considerando estos hechos debemos decir que aquella contingencia de la objetivación científica, de la que hemos hablado hasta ahora, presenta los caracteres de la que, en forma más significativa, podríamos llamar su determinación histórica" (Agazzi E. , 1996, pág. 44)"

However, such presence of subjectivity in the analogical rationality installs the cognitive process of science as a human activity, and therefore, completely axiological; "the existence of values and its determination appear as an essential feature in the explanation of the actions and human institutions" (Agazzi E. , The good, the bad and the science, 1996, p. 169). These statements clearly show certain attributes of contextual, inherent in the pragmatic condition of this conception of rationality, and in which the reference to the values permeates all human operations. About this, Agazzi affirms that it can even be said that human activities:

Muy a menudo se explican, en sus últimas razones, mediante la presencia de valores. La prudente limitación expresada por nuestro «muy a menudo» traduce simplemente el reconocimiento de la posibilidad de operaciones y de prestaciones humanas que son realizadas exclusivamente en vista de un objetivo pragmático, y que no obstante son "humanas». (Agazzi E. , 1996, pág. 176)

ii) Nonetheless, concerning the intersubjective agreements with respect to the scientific objectivity, what is being proposed here such agreements equally require of self-determination processes that are inherent to the objects, making possible, on the one hand, methodologically, that the experiments were repeated. This repeatability according to the agazzianos approaches turns out to be a necessary condition "for verification, authentic heart of all the scientific methodology". (Agazzi E. , 1978, p. 415), Thus, overcoming any possible subjectivity. Moreover, on the other hand, leading to the claim and/or data on the subject of social facts that are controlled, according to the operational criteria of observation and verification of each specific science (strong objectivity).

This determination of the objects is possibly made through operational and referentiality criteria, which allows the facto not only by cutting the objects in a state of things of reality, but also making possible to reach the truth concerning the regional ontologies of each science in particular. How Agazzi says:

Indeed, the operational criteria of truth that we have presented are at the same time criteria of reference in the sense of determining the domain of objects of a given science, and this is precisely the regional ontology it is expected to explore and to which belong also the 'unobservable' entities postulated by its theories. (Agazzi E. , Scientific Realism Within Perspectivism Perspectivism and Within Scientific Realism, 2016, p. 360)

In this regard, it is pointed out that such operational criteria of objectification and ontological referential never deals with the whole of reality, but with a field exclusively focused and specific objects within the state of things in the whole of reality, making reference to the ontological aspect of knowledge, and as it had already been exposed before, from the 
ontological conditions-, since the adoption of a given set of such criteria 'clips out' some particular object, while the adoption of a different set of criteria 'clips out'. A different object, both from one and the same individual 'thing" (Agazzi E. , 2014, p. 89). This Ontological relativity recognizes that a particular science never deals, as it was mentioned, according to the philosopher Bergamo, "the domain name of the 'reality', but rather, within this, designates the scope of specific 'objects' through some 'predicates', which can be considered as representative of his point of view about the reality" (Agazzi E. , 2000, p. 54) establishing that such predicates come from a particular science and giving his legitimacy character as well.

\section{Conclusions}

As a result, this debate on the rationality in the sciences in general, with special attention to the social science, is then installed as a philosophical current and necessary exercise, which seeks to understand and explain how it expresses the human faculty of "reason". Thus, that "reason" allows the social sciences give an account or methodically approach to the problem of truth, and what is the way in which the rationality or "certain types of rationality" work (Agazzi E. , 2004, p. 245 ) in accordance to the various social sciences. That is to say, the recognition of all those "criteria of rationality adopted within each scientific discipline" (Agazzi E. , 1996, p. 45).

Also, since this proposal of analogical rationality argument that is unviable for scientific practice, as it was intended to make the classical rationality- to determine unequivocally, a set of rules or algorithms whose principle is a priori, evident by itself and not necessarily shared in the process of rational choice to avoid human contingencies. For this reason, through this written and in contrast to the claim of the classical nature of rationality, it is proposed to conceive the ontological, epistemic, pragmatic conditions in a similar and proportional manner, in other words, analogical for science in general, as determining factors in the justification process of beliefs and rational choices. This proposal focuses the attention of the rationality in the individuals, intersubjectivity, the context, the values, the scientific communities and the epistemic purposes and interests verified by criteria of rigor and objectivity, in accordance with the specific or regional ontologies inherent to each social science.

\section{About the author}

Professional in Philosophy from the University of Quindío. Specialist in University Teaching and pedagogy from the Gran Colombia University. Master's degree in Philosophy from the University of Valle and a PhD candidate in Philosophy at the Pontificia Bolivariana Univiersity in Medellin. Teaching and research at San Buenaventura University in Cali. Faculty of Education. Research Group Education and Human Development. E-mail: Carengifo1@usbcali.edu.co careca1106@gmail.com Avenida 10 de mayo, La Umbría, Vía a Pance - Cali, Colombia, South América.

\section{Acknowledgement}

This article is the result of the research project called: "Rationality and progress in science. A proposal for analogical rationality, from the epistemology of Evandro Agazzi" developed in the doctorate in Philosophy from the Pontificia Bolivariana University. This project is supported by the research directorate of the San Buenaventura University in Cali (Colombia). Cost Center number 34516035. Thanks to professor German Guerrero Pino PhD who advised this doctoral research project.

\section{References}

[1] Agazzi, E. (1978). Issues and problems of philosophy of physics. Barcelona: Herder.

[2] Agazzi, E. (1996). The good, the bad and the science. Madrid: Tecnos.

[3] Agazzi, E. (2000). Philosophy of Nature. Science and Cosmology . Mexico: Fondo de Cultura Económica.

[4] Agazzi, E. (2004). The Challenge of Interdisciplinarity: difficulties and achievements. Enterprise and Humanism, 241-252.

[5] Agazzi, E. (2007). The science and the knowledge of the truth. Unpublished (Magistral University of Mendoza), 7.

[6] Agazzi, E. (2009). Che thing è within e che thing è fuori dalla scienza a riflessione philosophical. Annuario, 2763.

[7] Agazzi, E. (2011). Consistency, Truth and Ontology. Mexico: Studia Logic. 
[8] Agazzi, E. (2014). Ethics of Scientific Research. Unpublished paper in the Interdisciplinary Department of bioethics, 6 .

[9] Agazzi, E. (2014). Scientific objectivity and Its Contexts. Heidelberg. New York, Dordrecht, London: Springer .

[10] Agazzi, E. (2016). The exercise of the intelligence in the different ontologies regional scientific research. Universidad Autónoma Metropolitana/Cuajimalpa, Mexico, 7.

[11] Agazzi, E. (2016). Scientific Realism Within Perspectivism Perspectivism and Within Scientific Realism. Springer Science+Business, 349-365.

[12] Alai, M. (2009). IL REALISM SCIENTIFICO DI EVANDRO AGAZZI. In M. Alai, IL REALISM SCIENTIFICO DI Evandro Agazzi (p. 172). Urbino: Editrice Montefeltro.

[13] Alai, M., Buzzoni, M., \& Tarozzi, G. (2015). Science Between Truth and Ethical Responsibility. New York: Springer.

[14] Alonso, G. J. (1997). The epistemology of Evandro Agazzi. Pamplona: University of Pamplona.

[15] Alvarez Lopez, M. B. (s.f.). Alvarez Lopez, M., Bernal López, L. A., Rengifo Castañeda, C. A., \& Canaveral Londoño, D. C. (2017). The rationality in the teaching and learning of the

[16] Beuchot, M. (2004). Hermeneutics, analogy and symbol. Mexico: Herder.

[17] Beuchot, M., \& Santamaría-Velasco, F. (2015). On the analogical reference. Writings, 311-330.

[18] Brown, H. (1990). Rationality. Great Britain: Pastdow.

[19] Brown, H. (1998). The New Philosophy of Science. Madrid: Tecnos.

[20] Ferrater Mora, J. (2000). Dictionary of Philosophy Took II. Buenos Aires: Sudamericana.

[21] Kitcher, P. (2001). The Advancement of Science. Mexico: Institute of Philosophical Research.

[22] Nozick, R. (1995). The nature of rationality. Cambridge : Cambridge University Press.

[23] Olive, Leon. (2006). Epistemic rationality. In L. Olive, epistemic rationality (p. 278). Madrid: Trotta.

[24] Perez Fishel, A. R. (2006). Rationality and scientific development. In L. Olive, epistemic rationality (p. 278). Madrid: Trotta.

[25] Putnam, H. (2001). Reason, truth and history. Madrid: Tecnnos.

[26] Rescher, N. (1993). The rationality. A philosophical inquiry about the nature and justification of the reason. Madrid: Tecnos.

[27] Rescher, N. (1995). The struggle of the systems. Mexico: Institute of Invetigaciones Philosophical . 